\title{
A ludicidade presente na vida das educadoras sociais: reflexos no trabalho com crianças abrigadas
}

\author{
Andrea Perosa Saigh Jurdia, Caroline Scridelli ${ }^{b}$ \\ aDepartamento de Saúde, Educação e Sociedade, Universidade Federal de São Paulo - UNIFESP, Santos, SP, \\ Brasil

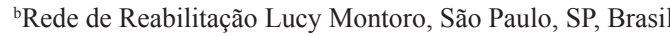

\begin{abstract}
Resumo: Educadoras sociais/cuidadoras são profissionais que cuidam física e emocionalmente das crianças em acolhimento institucional, sendo as responsáveis pelos cuidados diários de alimentação, higiene, bem como pelo afeto e pela ludicidade inerente a essa fase do desenvolvimento. Este estudo teve por objetivo investigar como a ludicidade está presente no trabalho e no cotidiano de oito educadoras sociais que têm por função cuidar de crianças abrigadas em uma instituição de acolhimento no município de Santos, SP. O desenho metodológico estruturou-se a partir de encontros semanais, nos quais houve a construção de narrativas orais das educadoras a respeito do brincar na sua infância, como ele continua nos dias atuais, sua concepção do brincar e como o brincar tem relação com sua função de cuidadora. Pôde-se verificar que para algumas educadoras o brincar na infância foi quase inexistente, mas conseguiram retomar sua função através dos filhos e laços familiares. Encontraram-se na instituição educadoras com excesso de responsabilidades na prática cotidiana e um número reduzido de profissionais, dificultando a relação adulto-criança. Como resultado observou-se que o brincar, em muitos momentos, fica dissociado da prática profissional. O cuidado com o brincar é uma das faces do acolhimento e do cuidado com crianças. O papel do adulto é fundamental para que a experiência de estar com o outro humano, em uma relação de confiança, possa possibilitar a criatividade de ambos - criança e adulto.
\end{abstract}

Palavras-chave: Cuidadores, Criança institucionalizada, Jogos e Brinquedos.

\section{Playfulness in the life of social educators: reflections on the work with children in shelters}

\begin{abstract}
Social educators/caregivers are professionals who care physically and emotionally for institutionalized children, being responsible for fulfilling daily needs such as hygiene and feeding, as well as for the affection and playfulness inherent to this phase of development. This study aimed to investigate how playfulness is present in the work and everyday routines of eight social educators who care for children sheltered in a host institution in the municipality of Santos, Sao Paulo state. The methodological design was structured from weekly meetings in which the educators constructed oral narratives about play in their childhood, how it is today, their conception of play, and how play is related to their function of caregivers. We verified that play was almost nonexistent in the childhood of some of the educators investigated, but they have managed to recover its function through their children and family ties. In this institution, we observed educators with excessive responsibilities in their everyday practice and a reduced number of professionals, which hinders the adult-child relationship. We observed that, as a result, play is many times associated with professional practice. For these educators, caring for play is one of the faces of hosting and caring for the children. The role of the adult is crucial to enable the creativity of children and adults based on the experience of being with other humans.
\end{abstract}

Keywords: Caregivers, Institutionalized Child, Play and Playthings.

Autor para correspondência: Andrea Perosa Saigh Jurdi, Departamento de Saúde, Educação e Sociedade, Universidade Federal de São Paulo, Rua Silva Jardim, 136, Vila Mathias, CEP 11015-020, Santos, SP, Brasil, e-mail: andreajurdi@gmail.com

Recebido em 11/10/2013; $1^{a}$ revisão em 21/3/2014; $2^{\text {a }}$ revisão em 30/5/2014; $3^{\text {a }}$ revisão em 11/6/2014; Aceito em 15/6/2014. 
Ao longo da história, a atenção à criança e ao adolescente brasileiro ficou circunscrita a um ideário de proteção que teve como consequência a construção de um modelo de assistência baseado na institucionalização e medicalização, gerando uma concepção não integradora da população infanto-juvenil.

A concepçáo higienista e saneadora da sociedade atuou sobre os focos da doença e da desordem, principalmente sobre o universo da pobreza, moralizando-o. Criou-se uma lógica normativajurídica que estabeleceu como atençáo e cuidado a oferta de instituições fechadas sob tutela de entidades filantrópicas. Garantir a paz e a saúde do corpo social era função do Estado e a criança passara a ser um dos principais instrumentos de intervenção na família. Assim, à criança pobre, cujo seio familiar era visto como ignorante, mas não imoral, reservava-se o cuidado médico e o respaldo higienista. À criança que perdia sua inocência, logo, considerada pervertida e criminosa - a justiça (RIZZINI, 2008).

$\mathrm{O}$ resultado desse processo que garantia a institucionalização do cuidado e a criminalizaçáo da infância pobre gerou um quadro de desassistência, abandono e exclusão. O movimento de redemocratização do país, com a promulgação da Constituição de 1988, teve o mérito de afirmar sem ressalvas a condição cidadã de crianças e adolescentes, assegurando-lhes, no art. 227, o direito à vida, à saúde, à educação, ao lazer e à cultura, ressaltando que o direito de proteção de toda forma de negligência, discriminação, exploração, violência, crueldade e opressão será garantido pelo Estado. A Constituição Brasileira de 1988 expressou o fim da estigmatização formal pobreza-delinquência e pôde-se pensar em uma nova legislação: o Estatuto da Criança e do Adolescente (ECA), que rompeu com a doutrina da situação irregular e estabeleceu a proteção integral na concepção da criança e do adolescente como sujeitos de direitos.

Segundo o ECA, o acolhimento institucional é uma medida de proteção às crianças e adolescentes e estabelece nos artigos 22 e 24 que o encaminhamento aos serviços de acolhimento deverá ser realizado quando esgotados todos os recursos para a manutenção das crianças e adolescentes na sua família de origem, extensa ou comunidade, a fim de causar o menor prejuízo possível ao seu processo de desenvolvimento (BRASIL, 2005).

Nesse sentido, o ECA inaugura um novo olhar e tratamento às questóes da infância e da juventude ao regulamentar a aplicaçáo das medidas socioeducativas e de proteção, levando ao estabelecimento de políticas de atendimento variadas. $\mathrm{O}$ abrigo como uma das medidas de proteção especial previstas no art. 101 do Estatuto tem o intuito de romper com a figura das instituições asilares para crianças e adolescentes.

Entretanto, o Levantamento Nacional de Abrigos para Crianças e Adolescentes da Rede de Serviços de Ação Continuada (Rede SAC) do Ministério do Desenvolvimento Social, realizado pelo IPEA/ CONANDA (BRASIL, 2009), mostrou que a institucionalização se mantém, ainda nos dias atuais, como caminho utilizado indiscriminadamente - e, muitas vezes, considerado o único possível - para a "proteçáo" da infância e da adolescência, demonstrando que o princípio da excepcionalidade da medida de abrigo, contemplado de maneira expressa pelo art.101, par. único, do Estatuto não vem sendo respeitado.

De acordo com o referido estudo, existem cerca de 20 mil crianças e adolescentes atendidos nas 589 instituiçôes de abrigos beneficiados com recursos do governo federal repassado por meio da Rede SAC. Os dados levantados mostram características típicas de exclusão social, apontando que os abrigos no Brasil são o lócus da pobreza e da desvalorização social.

O cumprimento das determinaçóes do ECA coloca para os abrigos a necessidade de profissionalização da atenção que oferecem, substituindo a prática da caridade que tem por objetivo a manutenção da sobrevivência por uma prática de caráter efetivamente protetor. Para Galheigo (2003), os abrigos devem ser, além de espaços de acolhimento e cuidado que substituam a família, espaços que promovam a (re) construção de laços afetivos e a (re)elaboração das situaçôes de sofrimento psíquico para que se vislumbre a possibilidade de uma vida plena e saudável.

Para a autora, há a necessidade de se pensar em uma política de recursos humanos que preveja uma contratação criteriosa, a capacitação de cuidadores, educadores e técnicos e a construçáo de projetos com açóes programáticas delineadas. Com essa mudança, os profissionais que se veem envolvidos em trabalhos nos abrigos têm procurado compreender seu papel no novo cenário político, participando da construção coletiva de um projeto de abrigo de caráter interdisciplinar, em que profissionais de diferentes formaçôes possam contribuir para elaboração de um projeto de atenção que contemple ações territoriais, institucionais, familiares, grupais e individuais.

A experiência de abrigamento para crianças envolve perdas, rupturas de laços sociais e familiares. Elas são obrigadas a passar pelo grande desafio de incorporar em sua vida cotidiana outro mundo, outras referências, nem sempre as que desejava para si própria. Seu universo familiar é substituído 
bruscamente pela instituição que a recebe. Isso pode acarretar mudanças em sua identidade, em seus alicerces de sustentação, sua cultura, entre outros. Passado, presente e futuro se abalam e a criança perde sua sensação de segurança, ficando, assim, sem saber o que de fato vai acontecer consigo (TINOCO, 2001).

Os educadores sociais são profissionais que trabalham com essas crianças em situação de vulnerabilidade causada por rupturas familiares, violência e abandono cujo papel vai além do auxílio nas atividades de vida diária das crianças, passando também pelas atribuiçóes domésticas e pelo cuidado emocional.

A formação necessária para que esses educadores possam trabalhar com a complexidade apresentada pela história de vida dessas crianças atendidas, muitas vezes, é inexistente ou precária. As consequências são extremamente desfavoráveis à saúde mental das crianças que ali estão e à própria saúde mental do educador que, impactado pelas histórias e reaçóes apresentadas pelas crianças, acaba por recorrer à excessiva disciplina e rigor para se proteger do desconhecido.

As atividades de extensão desenvolvidas com crianças abrigadas nos permitiu problematizar a complexidade da função e do papel das educadoras sociais, também nomeadas cuidadoras. A fragilidade do papel que exercem se assemelha à própria fragilidade dos abrigos que vivem à margem, longe da atençáo social e, muitas vezes, sem condiçóes adequadas de atendimento. Assim, a função de cuidado que deve ser exercida pode ser negligenciada em função das lutas cotidianas travadas pela instituição e pelas cuidadoras.

O referencial adotado neste estudo, a teoria do amadurecimento, nos permite compreender o crescimento do indivíduo no encontro com o ambiente. Para as pessoas que exercem a função de cuidar do outro, esse princípio continua sendo um importante analisador de como o cuidado é exercido. As pessoas que cuidam também dependem dessas tendências para exercerem seu papel de forma satisfatória e a responsabilidade delas acerca do desenvolvimento humano encontra-se sobre a capacidade que tiverem para lidar adequadamente com o que for se apresentando. Nesse sentido, este artigo faz uma reflexão sobre o fruto de uma pesquisa com oito educadoras sociais que trabalham em uma instituição de acolhimento na cidade de Santos, $\mathrm{SP}$, a qual teve como objetivo investigar o lugar da ludicidade no cotidiano e na vida desses sujeitos e a sua importância no trabalho com crianças em situação de acolhimento institucional.

\section{O cuidado sob a óptica da teoria do amadurecimento}

Para Winnicott (1975), a criatividade relaciona-se ao estar vivo, à capacidade de o indivíduo de criar a realidade extern, e ao fato de o ambiente poder, desde o início da vida desse bebê, atender ao seu impulso criativo que, acolhido pelo ambiente, demonstra a necessidade de ser do bebê, pois o gesto, o encontro e a experiência se tornam reais. É da ilusão de onipotência que nasce a capacidade de acreditar que é a base para a capacidade da crença no próprio viver.

Em seu processo evolutivo, a criança afrouxa os laços da dependência familiar e passa a integrar a sociedade global e a apropriar-se da herança cultural, devendo o ambiente provê-la nesse sentido. No entanto, quando o ambiente é repetidamente insuficiente, obriga essa criança a reagir e a substituir seu gesto espontâneo pela submissão, adaptação e imitação. Por outro lado, o ambiente que acolhe o gesto criativo permite ao indivíduo mostrar sua presença que, no registro individual, significa a capacidade de se sentir vivo, real e atuante numa realidade que nos coloca frente a frente com a alteridade irredutível do mundo. No registro coletivo, presença significa a possibilidade de subjetividades coletivas ocuparem tempo e espaço sem que sejam obrigadas a lutar tenazmente pela sobrevivência, fazendo uso de dissociaçôes defensivas (VAISBERG, 2004),

Para tanto, se faz necessário pensar em uma provisão ambiental que possibilite à criança envolver-se criativamente em seu processo de amadurecimento. Nessa perspectiva, prover para a criança é uma questáo de prover o ambiente que facilita a saúde mental individual e o desenvolvimento emocional, sendo saúde considerada como maturidade de acordo com a idade do indivíduo. Um ambiente suficientemente bom oferece a continuidade do ambiente humano, que auxilia a integração da personalidade do indivíduo; a confiança é o que torna o comportamento do ambiente previsível e a adaptação gradativa às necessidades cambiantes em expansão da criança é a provisão para concretizar seu impulso criativo.

A teoria afirma a importância do brincar não apenas para as crianças, mas, também, em relação aos adultos, uma vez que esse brincar se dá na superposição de dois espaços de brincar, estando relacionado a duas pessoas que brincam juntas. É por meio da atividade lúdica que o indivíduo se apropria da experiência cultural. Como atividade 
humana, abre possibilidades para um campo em que as subjetividades se encontram com elementos da realidade externa, possibilitando uma experiência criativa com o conhecimento.

O brincar na teoria winnicottiana ganha um estatuto próprio e abre outra possibilidade de compreensão do indivíduo e de sua relação com o ambiente. O brincar winnicottiano é expressão da criatividade, da possibilidade de o indivíduo criar o mundo por meio de seu gesto espontâneo. Estamos falando de um brincar que tem espaço e lugar para acontecer, tanto na subjetividade de cada um como na realidade compartilhada. Um brincar que se propóe criativo, pois o entrelaçamento com o ambiente faz com que o indivíduo possa criar e transformar, colocar algo de seu no mundo compartilhado. Mello Filho e Leal refletem sobre o viver criativo, noção introduzida pela teoria winnicottiana, que remete à maneira como o indivíduo segue seu percurso, no contato com a realidade, sem perder o que é genuinamente seu: sua subjetividade (MELLO FILHO; LEAL, 1995).

É no brincar que a criança e o adulto fruem sua liberdade de criação e, assim como a experiência cultural, pode receber uma localização: o espaço potencial existente entre máe e bebê. $\mathrm{O}$ autor chama a atenção para o fato de que náo se pode fazer uma descrição do desenvolvimento inteiramente em termos do indivíduo e, sim, considerar que o comportamento do ambiente faz parte do próprio desenvolvimento pessoal do indivíduo e, portanto, tem de ser incluído.

Esse referencial teórico chama a atenção para a importância de uma terceira área, a da brincadeira, que se expande no viver criativo e em toda vida cultural do homem. Essa área, chamada área da experiência, está localizada no espaço potencial entre indivíduo e ambiente. Variável de indivíduo para indivíduo, a realidade pessoal e o mundo real permanecem relativamente constantes, sendo a primeira determinada biologicamente e o segundo, propriedade comum. Nesse sentido, o espaço potencial entre o bebê e a mãe, entre o indivíduo e a sociedade ou o mundo, depende da experiência que conduz à confiança, permitindo que ele experimente o viver criativo (WINNICOTT, 1975).

Cada educador traz sua história e experiência pessoal e, muitas vezes, observamos que essas histórias trazem lembranças de uma infância difícil. Trazer à tona as reflexóes acerca dessa experiência e como ela permanece nos dias de hoje e repercute no trabalho com as crianças é fundamental para provocar modificaçóes no cuidado e no acolhimento de crianças abrigadas.

\section{Materiais e método}

O estudo realizado seguiu os preceitos da metodologia qualitativa e permitiu a compreensão da lógica interna do grupo de educadoras, da instituição, da história e as relaçôes que ali acontecem (MINAYO, 2008). Nesse sentido foi possível desenvolver um estudo que ouviu os atores - as educadoras e o conhecimento da história. A abordagem qualitativa veio ao encontro do objetivo do estudo ao permitir trabalhar com o universo de significados, aspiraçōes, crenças e valores e ao transitar entre a realidade, as políticas que envolvem essa área de trabalho e o cuidado com a infância.

\subsection{Local do estudo}

O estudo foi realizado em uma unidade de acolhimento institucional localizada na cidade de Santos, SP, que atende crianças de 0 a 6 anos em situaçáo de abandono, maus tratos e riscos. Quando há a necessidade de acolhimento de irmãos, abre-se exceção para crianças mais velhas. Essas chegam à instituição via Conselho Tutelar e Poder Judiciário e permanecem até a determinação do Juiz da Infância e da Juventude, que estabelece se voltarão para a família ou serão encaminhadas para guarda e adoção.

A instituição na qual foi desenvolvido o estudo existe no município desde 1986 e é mantida com recursos obtidos com a realização de eventos, doaçôes e convênios com a prefeitura municipal. No momento do estudo, a instituição abrigava cerca de 35 crianças cuja faixa etária variava entre 0 e 19 anos. A justificativa da coordenação da instituição para a presença da faixa etária acima dos 6 anos é que os grupos de irmáos foram crescendo e, consequentemente, as idades se estenderam. O quadro de funcionários da entidade é de duas funcionárias na parte administrativa, três na cozinha e três na limpeza, uma assistente social, uma psicóloga (não é exclusiva da instituição e é acionada em caso de necessidade), uma coordenadora, 16 educadoras sociais, 10 funcionários de telemarketing e quatro motoboys, total de 31 funcionários. Conta, ainda, com o auxílio de voluntários que possuem uma ficha de cadastro onde informam o dia que estarão na instituição.

As crianças são divididas por faixa etária: B1 (0 a 1 ano), B2 (2 a 5 anos) e B3 (6 a 19 anos). As educadoras sociais se dividem por grupo de crianças e são fixas. A instituição tem como princípio não fornecer dados da história de vida das crianças e sobre os motivos de sua ida para a instituição para as educadoras. Essas devem ter ensino médio completo, 
no entanto essa instituição prioriza no momento da contratação pessoas que já conheçam a casa e que já atuaram como voluntárias. As educadoras organizam-se por períodos e dias da semana. Uma equipe trabalha de segunda a sexta-feira, outra, apenas aos finais de semana e feriados e outra, no período noturno.

Em relação à sua formação, as educadoras realizam cursos de capacitação à época de sua contratação e que se repetem, com encontros realizados uma vez por mês. Os temas englobam noções básicas de higiene, doenças, primeiros socorros, cuidados gerais com crianças, desenvolvimento humano, sexualidade, drogas. As educadoras participam das temáticas de acordo com a faixa etária com a qual trabalham. À época do estudo, os encontros estavam sendo realizados esporadicamente.

A instituição foi escolhida em virtude de possuir uma parceria com a Universidade Federal de São Paulo - Campus Baixada Santista, permitindo a coleta de dados. A coordenadora da instituição foi contatada para apresentação do trabalho. Após a avaliação do projeto pela direção da instituição, o projeto foi submetido ao Comitê de Ética e Pesquisa em Seres Humanos e aprovado conforme parecer n. 16.197 .

\subsection{Construção de narrativas}

A produção de dados foi realizada por meio de pesquisa bibliográfica e pesquisa documental que buscou conhecer as leis e políticas públicas existentes e a construçáo de narrativas de acordo com as etapas descritas a seguir.

Foi realizado um levantamento de artigos científicos que tivessem como descritores: criança institucionalizada, abrigo, educadores de crianças abrigadas, ludicidade e brincar nas bases de dados Scientific Eletronic Library Online (Scielo), Literatura Latino-Americana e do Caribe em Ciências da Saúde (Lilacs). Esse levantamento se fez necessário para saber sobre trabalhos que abordassem o tema e a relevância do estudo. Nos artigos encontrados, o brincar aparece como recurso para o trabalho e cuidado com as crianças, porém nada foi encontrado em relação à ludicidade do educador ou sua importância no trabalho com crianças. Além disso, foi preciso conhecer os documentos, legislação e políticas públicas existentes para analisar o lugar do educador social nesse panorama.

O método de construção de narrativas foi escolhido por proporcionar ao narrador a possibilidade de trazer elementos que vão além dos objetivos academicamente elaborados. A narrativa permite ao personagem (narrador) reviver um tempo passado no presente e com isso ser capaz de reinterpretá-lo à luz das possibilidades do futuro. Possibilita que passado, presente e futuro, toquem-se e transformem-se mutuamente (VASCONCELLOS, 2008).

Para a construção das narrativas utilizou-se um roteiro para nortear as questóes mais relevantes para a pesquisa, porém pretendeu-se priorizar o processo de produção de dados de forma que o diálogo mais livre pudesse acontecer. As narrativas foram gravadas e transcritas em comum acordo com as narradoras.

Inicialmente foi realizada uma entrevista semiestruturada com a coordenadora da instituição, que forneceu à pesquisadora história, organograma e dados gerais sobre a contrataçáo de educadores e a rotina institucional. Após essa entrevista, o estudo foi apresentado às educadoras, que assim que acordaram com sua participação no projeto assinaram o Termo de Consentimento Livre e Esclarecido. Após esse procedimento iniciou-se a coleta de dados. Participaram da pesquisa oito cuidadoras, sendo duas do B1 (que cuidam dos bebês), três do B2 (que cuidam de crianças de 2 a 4 anos) e três do B3 (que cuidam de crianças de 4 a 6 anos). Dessas, cinco trabalham no período da manhã, uma, no período da tarde e duas, aos finais de semana.

Foram realizados mais de 20 encontros entre a conversa inicial de apresentação do projeto e a elaboração das narrativas Os encontros aconteceram quase diariamente e não possuíam um tempo determinado, ocorrendo entre junho e agosto 2012.

\subsection{Diário de campo como instrumento de produção de dados}

As conversas, impressões, anotações foram registrados em um diário de campo que teve como função apoiar os dados coletados nas construçôes de narrativas. Além disso, o diário de campo foi utilizado pela pesquisadora como recurso para produção de dados, uma vez que compóem o corpo da pesquisa o olhar e o posicionamento da pesquisadora, assim como a observação da rotina, das relaçóes de trabalho que se desenrolavam na instituição e de como o brincar acontece na rotina das crianças e educadoras.

\subsection{Análise dos dados}

Essa etapa constituiu na ordenação dos dados, na leitura e releitura do material coletado por meio das leituras, diários de campo e narrativas. Partindo-se 
da leitura repetida em consonância com o referencial teórico adotado, a análise dos dados foi realizada a partir de três temas que foram recorrentes nas histórias narradas e que se mostraram importantes na prática profissional das educadoras: a infância e os desdobramentos na vida adulta, os diferentes papéis de tia, cuidadora e educadora social, bem como as concepções do brincar.

Para discutir a ludicidade presente na vida das educadoras partiu-se do princípio de que ela se manifesta na vida profissional e cotidiana de várias maneiras. $\mathrm{Na}$ vida profissional, se concebe um indivíduo que pode ser criativo, superar obstáculos, ter flexibilidade e ser capaz de oferecer um ambiente acolhedor, baseado na escuta e no cuidado. Na vida cotidiana, a ludicidade apresenta ressonâncias com religiosidade, atividades culturais, disponibilidade para o lazer e para atividades significativas.

\section{Resultados e discussão}

\subsection{A infância e os desdobramentos na vida adulta}

Algumas cuidadoras tiveram sua infância interrompida precocemente para assumir o cuidar dos irmãos menores enquanto os pais trabalhavam ou para trabalharem a fim de auxiliar no sustento da família. Outras relembram fortemente os desentendimentos ocorridos entre os pais, os quais deixaram marcas profundas na memória e na infância dessas profissionais, que se refletem, muitas vezes, no cuidado com os filhos:

Fiquei como mãe dos meus irmãos, falo que minha maternidade iniciou aos nove anos (Cuidadora 3).

Uma coisa que marcou muito minha infância foi ver minha máe chorando e quando fui perguntar o que era ela me falou que estava com dor de cabeça e só depois fui entender que não era dor de cabeça, era sofrimento e foi nesse momento que decidi não ter a vida igual à da minha mãe, foi uma promessa que fiz comigo mesma e com Deus (Cuidadora 4)

As fissuras na ludicidade provocaram reverberaçōes na vida adulta dessas mulheres bem como na oferta de um ambiente suficientemente bom e propiciador para o brincar de seus filhos:

Não tinha vida de moça, tinha vida de dona de casa e achava que se eu casasse tudo mudaria, iria trabalhar, ter liberdade, cuidar de mim, mas minha vida não mudou nada. Como tive filhos muito cedo, não tinha paciência para brincar com eles, tudo me irritava. Só casei para sair da minha casa e ficar livre do meu pai (Cuidadora 8).

Brinquei mais com os filhos das patroas do que com a minha própria. Não tinha tempo, chegava cansada do trabalho e ela já estava dormindo (Cuidadora 7).

Entretanto, houve aquelas que mesmo não tendo a participação dos pais na infância fizeram diferente com os filhos e as que puderam desfrutar tanto da ludicidade quanto da participaçáo deles nessa fase da vida:

Sempre procurava estar presente, era voluntária na escola dele, brinco com a minha filha, ensino as cores, dançamos juntas. Queria que meus filhos tivessem uma infância diferente da minha (Cuidadora 4).

Lembro que quando éramos pequenos minha mãe, depois que terminava os serviços da casa, sentava para nos contar histórias e brincava de boneca comigo (Cuidadora 11).

$\mathrm{Na}$ teoria do amadurecimento, as experiências da infância repercutem na idade adulta e contribuem para a construçáa do reservatório de criatividade do adulto, refletindo-se nas atividades de lazer que nada mais são do que a essência da ludicidade nessa fase do desenvolvimento humano.

Em meus momentos de lazer gosto de assistir filmes, dançar, ir ao shopping, ir à praia com as amigas e ficar perto de quem gosto (Cuidadora 4).

Posso te dizer com toda certeza de que hoje eu vivo... meus filhos já estão criados e eu aproveito para sair com meu marido para nos divertir (Cuidadora 3).

Não costumo fazer nada em meus momentos de lazer porque lazer de pobre é pagar conta, só (Cuidadora 8).

Em meus momentos de lazer gosto de sair com os filhos e com o meu marido para comer fora, ir ao cinema e aproveito, também, para descansar em casa. Esses momentos sáo muito importantes para mim, me permitem relaxar, porque apesar de eu gostar do meu trabalho, é muito estressante lidar com crianças e com adolescentes, eles exigem uma carga mental muito forte (Cuidadora 6).

A observaçáo realizada e os registros dos diários de campo mostraram que na prática diária de trabalho das educadoras o trânsito entre a brincadeira e a 
necessidade da disciplina e organização ainda é muito difícil para elas. Para responder às regras institucionais, manter a ordem e o silêncio torna-se a preocupação principal e, muitas vezes, em detrimento de atividades mais criativas para as crianças e para si mesmas como trabalhadoras. Segundo Daffre (2012) e Oliveira (2009), a história e a experiência pessoal de cada cuidadora são marcadas por características singulares que se expressam nas ações cotidianas de seu trabalho. Para Winnicott (1975), a capacidade de o indivíduo criar, fazer, estabelecer uma ação no mundo iniciada na relação primordial com a mãe estende-se à vida adulta, sendo que o fazer criativo apenas emergirá se o indivíduo tiver uma relação com o ambiente sustentada na confiabilidade. Portanto, a ação do indivíduo não se dá de forma aleatória, vem impregnada de uma história, de sua inserçáo cultural, e influenciada pela resposta do ambiente às suas necessidades.

\subsection{Os diferentes papéis}

Segundo as Orientações Técnicas: Serviços de Acolhimento para Crianças e Adolescentes (BRASIL, 2009), não há distinção entre a nomenclatura educadora social e cuidador para designar o profissional responsável pelos cuidados com as crianças abrigadas.

Essa ideia é compartilhada por algumas cuidadoras, no entanto outras veem diferença nesses papéis e há aquelas que não conseguem desmembrar os múltiplos papéis desempenhados ao longo do seu cotidiano de trabalho, uma vez que eles se misturam e complementam-se durante suas atividades com as crianças:

Educador social, monitor, cuidador, tia representam a mesma função no abrigo, não existindo diferenças entre as nomenclaturas: aqui eles nos chamam de 'tia' porque não somos mães deles, mas meu papel aqui é igual de mãe: cuido, educo, por isso não vejo diferença nos nomes que você me falou (Cuidadora 9).

Há diferença entre ser cuidadora, educadora, tia: cuidadora é uma espécie de robô que chega, faz o seu trabalho e vai embora, tia é afinidade, convivio, e máe é afeto (Cuidadora 4).

Não sou mãe deles, mas tento passar esse papel, brinco, dou carinho. Eles moram aqui e eu cuido e educo eles como fiz com meus filhos, por isso é diferente de uma professora, que só ensina (Cuidadora 6).
Um aspecto recorrente na fala dessas mulheres é a presença da figura materna e das atribuições cabíveis a esse papel ocupacional. Talvez estejam referindo-se não a figura materna em si, mas sim ao que Winnicott (1990) designou de "mãe suficientemente boa": alguém capaz de oferecer um ambiente acolhedor e provedor de amadurecimento e assim assegurar um viver criativo na vida adulta das crianças abrigadas e que se encontram desprovidas desse cuidado.

São elas as responsáveis, muitas vezes, por fazer a transição entre a ilusão e a desilusão, por meio da prontidão com que atendem as necessidades biológicas (fome, frio, calor) e as emocionais das crianças e também por tecer relaçôes e construir identidades mediante a confiança proporcionada pelo ambiente durante o processo de infância, e isso faz com que a desvinculação com as crianças não seja tarefa das mais fáceis:

Logo que entrei aqui levei uma criança do B2 para passar as férias comigo, foi lindo. Resgatei todo aquele instinto materno de trocar fraldas, dar banho... mas quando precisei trazế-lo para cá novamente, doeu muito, chorei dias em casa. Agora procuro não levar mais as crianças para casa e policio-me para evitar tanto apego (Cuidadora 6).

É igual dentro de casa, a gente tem afinidade e se identifica mais com um filho do que com outro. Não tem como não se apegar, por mais que a gente não queira, se apega; e vemos isso quando a criança vai embora e que parece que uma parte da gente vai junto e percebemos que já estávamos apegadas e apaixonadas por ela. Procuro ter consciência durante todo o meu trabalho de que devo cuidar e dar carinho, mas que as crianças e adolescentes ali não me pertencem, mas isso nem sempre funciona (Cuidadora 6).

O Plano Nacional de Promoção, Proteção e Defesa da Criança e Adolescentes à Convivência Familiar e Comunitária (BRASIL, 2006) nos traz a questão da vinculação como responsabilidade legal da família quando a criança ou adolescente estão sob seus cuidados, bem como a vinculaçấo de caráter simbólico e afetivo, as quais são mediadas pelas relaçóes de amizade, apadrinhamento e as constituídas com a finalidade de assegurar a sobrevivência e socialização das crianças e adolescentes.

E é esse vínculo de caráter "simbólico" repleto de afetividade que as cuidadoras vivenciam uma vez exercerem a maternagem através do olhar, do tom de voz, da capacidade de estar presente e de pensar pela criança, como também pela paciência, pela flexibilidade, pelo prazer de cuidar e pela dedicação, e se veem às voltas, subitamente, com o fato de ter 
esse "filho" tirado bruscamente de seus braços, o que as deixa desamparadas (DAFFRE, 2012).

Evidenciou-se na prática cotidiana institucional das educadoras sociais que, independentemente da nomenclatura utilizada para designar sua funçáo no abrigo, a presença da mãe suficientemente boa é recorrente na rotina diária dessas mulheres, uma vez que são elas as responsáveis pela disciplina, pelos cuidados básicos de alimentação e higiene, pelo aporte social e emocional e também por possibilitarem um ambiente facilitador e propiciador do brincar. Complexidade essa expressa tanto na fala quanto na rotina das educadoras sociais.

\subsection{Concepções do brincar}

A ludicidade e o brincar trazem intrínsecas em sua definição as experiências de vida e aquelas vivenciadas na infância, permeadas pelas heranças culturais, conforme a teoria winnicottiana. Para Wajskop (1996), a brincadeira é uma atividade social aprendida nas interações sociais desde a mais tenra idade.

Brincar é ficar à vontade, é brincar junto, é oferecer brinquedos e ser feliz. Brinco junto com as crianças porque na hora que a gente fala firme com eles, eles veem a diferença, eles me respeitam (Cuidadora 3).

Brincar é estar com outras pessoas, relacionando-se e desenvolvendo-se como pessoa, além de aprender a respeitar uns aos outros. Brincar em grupo desenvolve gentileza, cumplicidade, o que falta na gente, né? (Cuidadora 6).

Brincar é um momento especial, é um momento de entrega (Cuidadora 4).

Uma cuidadora teve muita dificuldade em definir o que, segundo ela, representa o brincar, dificuldade essa expressa também em sua prática institucional e no cuidado com os filhos.

Brincar é... Não sei, tem várias maneiras, sei lá. Brincar é brincar (Cuidadora 8).

Apesar da importância do brincar compartilhado e de se oferecer um ambiente que propicie a ludicidade, essa prática não foi observada na maioria das atividades das cuidadoras. Embora tenham relatado a importância da atividade lúdica para as crianças abrigadas nas narrativas, na observação do cotidiano institucional, em função das atividades de cuidado, ordem e disciplina, de coordenar tantas tarefas e crianças, era frequente ouvir vozes alteradas, estresse, e desrespeito mútuo. Em função disso, há uma dificuldade em propiciar um ambiente facilitador da atividade lúdica.

O cuidado traduzia-se pela questão da ordem e, também, na preocupação em mantê-los sentados e em disciplina. Diante disso surge um questionamento de como estabelecer regras e limites sem que elas anulem a ludicidade dessas crianças.

Apesar disso e de tudo, as crianças brincam, as brincadeiras aconteciam a todo momento e eram permeadas pela rotina familiar (máe que leva o filho à escola e ao médico, dar banho, esperar o pai chegar do trabalho para todos jantarem juntos, conversas com a mãe pelo telefone celular, dizendo-lhe que não pode atender, pois está cuidando do filho) assim como pelos afazeres do abrigo.

Algumas cuidadoras não participavam das brincadeiras juntamente com as crianças, contudo não interferiam nelas e deixavam que elas mesmas resolvessem as diferenças que porventura surgissem no brincar.

Para que brincadeiras e ludicidade obtenham sucesso, nessa perspectiva do brincar, é preciso que os adultos que sustentam as práticas relativas às brincadeiras infantis tenham consciência de suas representaçóes nessa atividade, assim como do desenvolvimento infantil e de infância.

Quando tenho a oportunidade participo das brincadeiras de bonecas com as meninas, no começo elas me olhavam assustadas, mas agora interagem comigo numa boa, nem percebem a diferença da idade (Cuidadora 6).

O cuidado com o brincar é uma das faces do acolhimento e do cuidado com crianças. Muitas vezes, o cuidado com crianças se traduz pela higiene, alimentaçấo e o cumprimento de horários, porém pouco se leva em conta a necessidade de oferecer e compartilhar momentos de brincadeira compartilhada. O papel do adulto é fundamental para que a experiência de estar com o outro humano, em uma relação de confiança, possa possibilitar a criatividade de ambos - criança e adulto.

\section{Conclusão}

Este estudo investigou como o brincar está presente na vida das educadoras sociais, compreendendo que esse permanece na vida adulta e repercute na forma como lidamos com as situaçôes do dia a dia. Considera-se que no acolhimento e cuidado a crianças com histórias de ruptura, abandono e violência o cuidado deve ser considerado na formação de cada profissional. 
O brincar, para além de ser utilizado como recurso pedagógico ou terapêutico, é uma atividade de comunicação da infância e como tal deve ser considerado. $\mathrm{Na}$ teoria adotada neste estudo, a brincadeira se dá na superposição de duas ou mais áreas do brincar, nesse caso refere-se à criança e ao educador social e relaciona-se a duas pessoas que brincam juntas. Se o universal é brincar, quando esse não é possível o trabalho do adulto responsável deve ser orientado de modo a fazê-lo acontecer. Assim, o brincar no contexto desta discussão está sendo considerado de forma ampla, isto é, muito mais como uma qualidade da experiência vivida pelo indivíduo na relação com os outros e com os objetos.

Neste estudo focou-se a experiência vivida por educadoras sociais em relação ao brincar e como esse se manifesta na vida delas, seja pelas atividades de lazer ou pelo trabalho desempenhado com crianças. A experiência diz respeito àquilo que sabem, vivenciam e sentem em relação à ludicidade e define o seu modo de ser e seus conhecimentos no âmbito do brincar, com decisivas implicações para sua prática profissional (FORTUNA, 2011).

As crianças acolhidas institucionalmente apresentam diversas rupturas e fissuras em sua história de vida, logo, durante o período em que se encontram abrigadas possuem como referência de cuidado e atenção aqueles desempenhados pelas cuidadoras.

Encontrou-se na instituição educadoras sociais com excesso de responsabilidades na prática cotidiana. Um número reduzido de profissionais não permite que possam circular livremente com as crianças.

O brincar, em muitos momentos, encontrou-se dissociado de sua prática profissional, mesmo lidando com crianças, e pode-se inferir também, pelas histórias de vida, que a experiência que tiveram na infância e as dificuldades encontradas na vida atual geram uma dificuldade em considerar o brincar como atividade importante para o cuidado a crianças.

Associado a isso ainda há o medo e a insegurança das cuidadoras de constituírem vínculos com as crianças, em decorrência do risco da separação iminente. Assim, desprovidas ou precariamente asseguradas pelas leis e orientaçôes técnicas dos abrigos, essas profissionais sofrem e fazem sofrer, à medida que também são "abandonadas", e esse sentimento de abandono e insegurança refletem-se em sua prática por meio de um falar mais áspero, na ausência de um olhar afetuoso e no não brincar juntos.

Observou-se na prática diária de trabalho das educadoras que a preocupação não é propiciar um ambiente que facilite a realização de atividades lúdicas e criativas, mas sim manter a ordem.

No entanto, o ambiente suficientemente bom não depende apenas da experiência de vida das cuidadoras. As instituiçóes têm um papel importante se pensarmos o quanto esses equipamentos facilitam e propiciam às cuidadoras um acolhimento emocional por meio de reunióes de equipe, apoio psicológico, uma vez que elas precisam sentir-se acolhidas e cuidadas para oferecerem um bom cuidado. Galheigo (2003) refere que há a necessidade de se pensar em uma política de recursos humanos que preveja uma contratação criteriosa, a capacitação de cuidadores, educadores e técnicos e a construção de projetos com açôes programáticas delineadas. Com essa mudança, os profissionais que se veem envolvidos em trabalhos nos abrigos têm procurado compreender seu papel no novo cenário político, participando da construçáo coletiva de um projeto de abrigo de caráter interdisciplinar, em que profissionais de diferentes formaçóes possam contribuir para elaboraçáo de um projeto de atenção que contemple açôes territoriais, institucionais, familiares, grupais e individuais. Para o terapeuta ocupacional, o cuidado com a ludicidade deve fazer parte de sua intervenção nas instituiçóes de acolhimento. Ao considerar a importância da atividade na constituição e relaçáo do indivíduo com o ambiente, o terapeuta ocupacional tem um importante papel a ocupar na equipe interdisciplinar, que pode contribuir para a formação de cuidadoras e para o cuidado a crianças em situação de acolhimento.

Já a importância do brincar e das infinitas possibilidades de estudo que dele emergem possibilitou-nos compreender que esse aparece como uma possibilidade que a criança tem de viver criativamente, de vivenciar processos de saúde e de reverter processos de amadurecimento interrompidos. E, para o adulto, a importância do brincar se traduz na sua criatividade para superar obstáculos, sua confiança no mundo e na possibilidade de preocupar-se com o outro, propiciando, portanto, o cuidado e o encontro com o outro humano.

Dessa maneira, o papel dessas profissionais ao propiciar o brincar se dá em função do amparo e do apoio exercido por elas tanto na dimensão da presença, em estar junto, quanto na dimensão da sustentação física por meio da garantia da regularidade do ambiente.

Compreendemos que a dificuldade de propiciar um ambiente mediador entre necessidades e desejos das crianças e os limites e possibilidades da realidade externa oferece às educadoras sociais argumentos para exigirem políticas e legislação referentes ao 
acolhimento institucional de crianças e adolescentes com atenção específica para a sua prática profissional.

Este trabalho procurou mostrar a necessidade de se cuidar da infância de forma a se assegurar uma vida adulta saudável, criativa e capaz de permitir que a essência da ludicidade perdure nessa fase do desenvolvimento humano e reverbere na vida adulta e na prática profissional dos sujeitos, sobretudo, quando essa se desenvolve com crianças, sejam elas abrigadas ou não.

\section{Referências}

BRASIL. Conselho Nacional de Assistência Social - CNAS. Plano nacional de promoção, proteção e defesa do direito de crianças e adolescentes à convivência familiar e comunitária. Brasília: CNAS, 2006.

BRASIL. Ministério do Desenvolvimento Social e Combate à Fome - MDS. Orientaçōes técnicas: serviços de acolhimento para crianças e adolescentes. Brasília: MDS, 2009.

BRASIL. Ministério da Educação. Secretaria Especial de Direitos Humanos. Estatuto da Criança e do Adolescente. Brasília: Ministério da Educação, 2005.

DAFFRE, S. G. A. Realidade dos abrigos: descaso ou prioridade. São Paulo: Zagodoni, 2012.

FORTUNA, T. R. A formação lúdica docente e a universidade: contribuiçóes da ludobiografia e da hermenêutica filosófica. 2011. 425 f. Tese (Doutorado em Educaçâa)-Faculdade de Educação, Universidade Federal do Rio Grande do Sul, Porto Alegre, 2011.

GALHEIGO, S. M. O abrigo para crianças e adolescentes: consideraçôes acerca do papel do terapeuta ocupacional. Revista de Terapia Ocupacional da USP, São Paulo, v. 14, n. 2, p. 85-94, 2003.
MELLO FILHO, J.; LEAL, A. L. M. (Org.). Winnicott 24 anos depois. Rio de Janeiro: Revinter, 1995.

MINAYO, M. C. S. O desafio do conhecimento: pesquisa qualitativa em saúde. São Paulo: Hucitec, 2008.

OLIVEIRA, I. M. A narrativa como possibilidade de abordagem dos conhecimentos produzidos pelo professor sobre sua prática. In: JESUS, D. M. et al. (Org.). Inclusão, práticas pedagógicas e trajetórias de pesquisa. Porto Alegre: Mediação, 2009. p. 251-260.

RIZZINI, I. O século perdido: raízes históricas das políticas públicas para a infância no Brasil. São Paulo: Cortez, 2008.

TINOCO, V. O luto de crianças institucionalizadas em casas de abrigo. Burgo Paulista: CAF, 2001. (Trecho de material elaborado para o Curso para Educadores Módulo I do Projeto Semear, ministrado por Luciana Mazorra e Valéria Tinoco). Disponível em: <http://caf.org.br/ paginas/biblioteca/texto_valeria_tinoco.pdf $>$. Acesso em: 30 ago. 2012.

VAISBERG, T. A. Ser e fazer: enquadres diferenciados na clínica winnicottiana. Aparecida: Idéias e Letras, 2004.

VASCONCELLOS, T. Infância e narrativa. In: VASCONCELLOS, T. (Org.). Reflexöes sobre infância e cultura. Niterói: EdUFF, 2008. p. 105-126.

WAJSKOP, G. Concep̧̧̄ês de brincar entre profissionais de educação infantil: implicaçóes para a prática institucional. 1996. 242 f. Tese (Doutorado)-Faculdade de Educação, Universidade Estadual de São Paulo, São Paulo, 1996.

WINNICOTT, D. W. O ambiente e os processos de maturação: estudos sobre a teoria do desenvolvimento emocional. Porto Alegre: Artes Médicas, 1990.

WINNICOTT, D. W. O brincar \& a realidade. Rio de Janeiro: Imago, 1975.

\section{Contribuição das Autoras}

Andrea Perosa Saigh Jurdi orientou a pesquisa e colaborou com a análise e redação do texto. Caroline Scridelli trabalhou na elaboração, coleta de dados e redação do texto. 